\title{
Short-Sellers and Short Covering
}

\author{
James Clunie ${ }^{* *}$ \\ Scottish Widows Investment Partnership, U.K. \\ Peter Moles*** \\ University of Edinburgh Business School, U.K. \\ Tatiana Pyatigorskaya \\ Merrill Lynch Wealth Management, U.K.
}

This study fills an important gap in the literature on loss realization aversion. It shows how a 'sophisticated' sub-set of investors, namely short-sellers, react to losses. Using daily data on stock lending, we estimate the average price at which short positions were initiated, thus permitting a study of short-sellers' responses to their own book losses. We find that short-sellers close their positions in response to losses and not simply in response to rising share prices. This is a key result and a distinction from findings in related research. We conclude that short-sellers do not exhibit an aversion to realizing losses, but instead accept their losses or 'mistakes' systematically. Stocks subject to short-covering in this manner do not subsequently under-perform the market, and so there is no evidence of an investment performance cost (other than transaction costs) associated with immediately covering short positions that fall to an accounting loss. As short-sellers are believed to play an important role in the setting of prices, the results of this study have implications for asset pricing and market efficiency.

\footnotetext{
* The authors would like to thank reviewers and participants at the Multinational Finance conference in Edinburgh (2006) and the Midwest Finance Association conference in Chicago (March, 2009) for their helpful suggestions. We would also like to thank participants at the State Street Risk Forum (2007), the Edinburgh University Centre for Financial Markets Research (2008), the JP Morgan Quantitative Conference (2008) and the CFA/ INQUIRE seminar in London (February, 2009) for their ideas and suggestions. ** Scottish Widows Investment Partnership, 60 Morrison Street, Edinburgh, EH3 8BE, E-mail: James.Clunie@swip.com. ${ }^{* *}$ University of Edinburgh Management School, William Robertson Building, 50 George Square, Edinburgh, EH8 9JY, E-mail: Peter.Moles@ed.ac.uk, (Corresponding author)
}

(Multinational Finance Journal, 2009, vol. 13, no. 3/4, pp. 265-292)

(C) Multinational Finance Society, a nonprofit corporation. All rights reserved. DOI: $10.17578 / 13-3 / 4-5$ 


\section{Introduction}

There is no upper limit to the price at which a stock can trade. Consequently, there is no limit, in theory, to the amount of money that a short-seller can lose. This contrasts with the experience of long-only investors, where losses are limited to the amount of capital invested. Exposure to unlimited liability can have catastrophic consequences, including personal bankruptcy, and is thus an important consideration in risk management. In this paper, we use a relatively new commercial dataset to examine the response of short-sellers to losing positions. We find significant evidence that short-sellers cover their positions as losses grow. This is consistent with short-sellers' use of stop losses as a risk control mechanism. We relate our findings to the literature on loss realization aversion and the 'disposition effect', an observed regularity in many studies of investor behavior. Our evidence that short-sellers are not averse to realizing losses has important implications for asset pricing and market efficiency, providing a strong motivation for this research.

The literature on behavioral finance describes a number of investor biases, or apparent divergences from rational behavior. Amongst these is the tendency for investors to hold on to their losing stocks too long and sell their winners too early. Shefrin and Statman (1985) call this the 'disposition effect'. They seek to explain it by combining 'prospect theory' (Kahneman and Tversky, 1979) with the notion of 'mental accounting' (Thaler, 1985). Prospect theory modifies expected utility theory in two ways. It suggests that individuals assess outcomes through the change they bring to their current situation (or other reference state) and not through their effect on overall wealth; and that utility functions are concave for gains and convex for losses (but steeper to attain overall risk aversion). Thus, losses (from a reference state) are perceived by individuals as larger than positive changes of the same magnitude. This leads to predictions consistent with investors being averse to realizing losses. Mental accounting provides a framework for the way investors set reference points for the accounts that determine gains and losses. Where an investor creates separate 'mental accounts' for profits in each stock position and applies prospect theory to each account (ignoring interaction effects), a disposition effect would be observed. Whereas prospect theory on its own suggests a pure 'preference-based' explanation for the disposition effect, Shefrin and Statman (1985) suggest that psychological factors also contribute. An aversion to 
realizing losses is believed to have its roots in people's desire to avoid feelings of shame, regret and blame from others.

Early empirical studies into the disposition effect and loss aversion involved experiments on students. However, Christensen-Szalanski and Beach (1984) and Bonner and Pennington (1991) argued that student samples were not representative of the whole population and the majority of the later experimental studies were performed using different groups of market practitioners, including off-floor futures traders (Heisler, 1994), mutual fund managers (Brown et al., 1996), sellers in the housing market (Genesove and Mayer, 2001) and participants in the automobile market (Johnson et al., 2006). Odean (1998) tests the 'disposition effect' using customer account data from a U.S. discount brokerage house. He finds that the propensity to sell a stock declines as losses increase, but also observes that investors sell losing stocks in December - presumably using the end of the tax year as a self-control mechanism.

Burns (1985) and Holt and Villamil (1986) argue that due to training, regulation and other factors, the behavior of financial professionals is expected to differ from that of 'ordinary individuals'. The empirical evidence here is mixed. On the one hand, Locke and Mann (2000) find evidence to support the existence of a disposition effect amongst professional floor futures traders. They also find that relative aversion to realizing losses is negatively related to contemporaneous and future relative trading success. Coval and Shumway (2001) find evidence of additional intra-day risk taking as a response to morning losses amongst professional market makers at the Chicago Board of Trade. Garvey and Murphy (2004) examine data on a US proprietary stock-trading team and find evidence that the traders hold on to losing positions too long and sell their winners too soon. Cici (2005) studies 517 actively managed funds in the USA and finds that $37 \%$ are affected by the disposition effect. Furthermore, this disposition effect has an economically and statistically significant negative effect on fund performance. Xu and Singal (2009) find that about 30\% of US mutual funds exhibit a disposition effect and that these experience poorer performance and smaller fund flows than funds without such bias.

By contrast, Shapira and Venezia (2000) find that although the disposition effect is pervasive amongst their sample of clients of an Israeli brokerage firm, it is less prevalent amongst professional investors than amongst amateurs. Brown et al. (2002) examine daily Australian 
Stock Exchange share data and find that a pervasive disposition effect is less pronounced amongst traders instigating larger investments. This observation is "consistent with the notion that professional training and expertise reduces judgmental bias". Dhar and Zhu (2008) examine the trading records of a brokerage firm to identify individual differences in the disposition bias. They find empirical evidence that wealthier investors, and those in professional occupations, exhibit less bias. Furthermore, approximately one fifth of investors in their sample exhibit behavior opposite to the disposition effect.

Although Shefrin (2002) argues that "Get-evenitis [i.e. an aversion to realizing losses] afflicts both sophisticated and unsophisticated investors", there is some evidence in the literature that the disposition effect can be moderated amongst larger, more experienced investors.

Widespread aversion to realizing losses can have important implications for asset pricing. Locke and Mann (2000) suggest that behavioral biases could affect asset pricing through market microstructure. Accordingly, "evidence that professional traders also exhibit alternative behavioral tendencies would provide increased support for research on the systemic effects of behavioral financial models". Barberis et al. (2001) integrate 'loss aversion' into an asset pricing model and show that their enhanced model has superior predictive power to alternative models. Rabin and Thaler (2001) use 'loss aversion' to help explain some of the anomalies in expected utility theory. Grinblatt and Han (2004) develop a model of equilibrium asset prices driven by mental accounting and prospect theory, so as to generate outcomes consistent with the empirical evidence on the disposition effect. In the model, the differences between a stock's market price and its aggregate cost basis is positively related to the stock's expected future return. This creates a spread between a stock's fundamental value and its equilibrium price, and an under-reaction to information. Frazzini (2006) tests whether the disposition effect induces 'underreaction' to news, leading to return predictability. The author shows that post-announcement price drift is most severe when capital gains amongst mutual fund holders and the news event have the same sign. The magnitude of the drift depends on the capital gains (losses) experienced by the stock holders on the event date. Thus, a pervasive disposition effect amongst investors can influence the pricing of assets.

Da Silva Rosa et al. (2005) state that: "the disposition effect...challenges precepts of rationality underpinning neo-classical theories of financial markets." However, a defence against such a 
challenge would emerge if it can be shown that the 'disposition effect' reflects only the behaviour of unsophisticated investors who are price followers rather than price setters. Accordingly, examining the behaviour of short-sellers is important, as they are widely regarded in the literature as sophisticated and 'well-informed' market participants (see, for example, Senchack and Starks, 1993; Dechow et al., 2001; Ackert and Athanassakos, 2005; and Boehmer et al., 2008). Short-selling is an integral component of arbitrage, a trading process that in neo-classical finance involves exploiting asset pricing anomalies and, in so doing, helping to set asset prices and keep markets efficient. Evidence of a disposition effect bias amongst short-sellers could have implications for asset pricing and market efficiency. There is thus a strong motivation to investigate the response of short-sellers to losses and we explore this gap in the literature.

The closest study to ours is Gamboa-Cavazos and Savor (2007). In their work, the authors examine the behavior of short-sellers after changes in stock prices. They make use of monthly data on short interest obtained from NASDAQ and find that short-sellers cover their positions after stock prices increase. Using subsequent returns as a proxy for expected returns, the authors argue that such short-covering cannot be explained by expected returns. The authors interpret their results as evidence that short-sellers cannot or will not maintain short positions after suffering losses, thus "making arbitrage less effective than envisioned by the efficient market hypothesis." They put forward two suggestions to explain their results: capital constraints (see Shleifer and Vishny, 1997) and 'myopic loss aversion' (see Benartzi and Thaler, 1995; Barberis and Huang, 2001; and Haigh and List, 2005).

A limitation of the Gamboa-Cavazos and Savor paper is that it employs only monthly data on short positions, whereas we employ daily data in our study. A further limitation of the Gamboa-Cavazos and Savor paper is that the authors do not take into account the price at which a short position is initiated, so that they are unable to tell if a short position is at a loss or a profit. We estimate the cost basis of aggregate short positions for each day, allowing us to identify if a disposition effect exists amongst short-sellers.

The rest of this paper is organized as follows: Section II describes the data and section III describes the methodology used. Section IV contains results. Section V contains discussion and analysis. Section VI concludes. 


\section{Data}

To study short covering, it is necessary to use data of an appropriate frequency for examining the activities of stock lenders and short-sellers. Until recently, publicly available short-selling data for US stocks was only available with a monthly frequency. However, Cohen et al. (2007) find that almost half the securities lending contracts they study are closed out within two weeks. This suggests that monthly data could be inadequate for understanding the trading practices of short-sellers. The dataset used for this study incorporates daily data on shares borrowed from the United Kingdom. This higher frequency data allows for an appropriate degree of granularity for the study of short covering. Other studies that examine stock lending data include Geczy et al. (2002), who use private data based on a single lender of stock for a twelve-month period and D'Avolio (2002), who examines an eighteen month period of data from one stock lender. Our research draws upon a longer time period than either Geczy et al. or D'Avolio, and uses market-wide data on stock lending, thus removing the problem of substitution effects across lenders that might be present in studies based upon a single stock lender. Furthermore, in the United Kingdom, the Financial Services Authority did not impose any specific restrictions or controls on short selling for the duration of this study (whereas restrictions on short-selling such as up-tick rules and Regulation SHO existed at various times in the large stock markets of the USA and Japan). Instead, short-sellers are simply subject to general market and regulatory arrangements, including market abuse principles. A limited number of studies investigate short-selling using non-US data (e.g. Aitken et al., 1998, Biais et al., 1999, Poitras, 2002, Ackert and Athanassakos, 2005, Au et al., 2007, Loncarski et al., 2009). However, these studies do not involve an investigation into short covering, as considered in this paper.

Stock lending acts as a proxy for short-selling, as the process of short-selling generally requires stock to be borrowed to facilitate settlement of the trade. To examine short covering, we create a daily dataset using UK stock data from two sources: stock lending data from Index Explorers Ltd and market data from Datastream. ${ }^{1}$ This contains daily information on stock lending starting on September 3, 2003. At inception, this database included stocks from the 350 largest companies

1. Index Explorers data has also been used by Saffi and Sigurdsson (2007) and Mackenzie and Hendry (2008). 
traded on the London Stock Exchange. Over time, the coverage of companies in the database has increased through the addition of smaller capitalization stocks so that by the end date May 31,2007, there is stock lending data for 681 companies. The smallest capitalization stock is approximately $£ 25$ million (USD 40 million), as of 2007. A number of companies cease to exist at some point during the 45 months (979 trading days) studied and these are included in the database until the date of their de-listing. We make use of all stocks in the database and all dates in the sample for which stock lending data is available. We combine the stock lending data with market data on the companies in the lending database. To facilitate the estimation of abnormal stock returns, we collect stock returns data for the year before the start of the Index Explorers database. Our formation period runs from September 1, 2002 to September 1, 2003 and is used to estimate betas and other key information for each company. As a result, the dataset is an unbalanced panel of data for between 350 and 681 companies covering 979 trading days with 12 data items per firm day.

There are a number of limitations with using stock lending data to estimate short selling. First, shares do not need to be borrowed to undertake "naked" short-selling (i.e. short-selling where there is no intention of subsequently settling the trade). Naked short-selling for periods of one day or longer is unlikely to be common, however, as it involves failed settlement. Intra-day short-selling, though, does not require the delivery of stock for settlement at the end of the day, and so would not be revealed by daily stock lending data.

Second, stock lending occurs for a number of reasons other than short-selling. In general, borrowing stock results in the temporary receipt of legal ownership of the securities and so the borrower is entitled to dividends, voting rights, and so forth. Strategies exist to benefit from these arrangements. Christoffersen et al. (2002, 2005) demonstrate increases in securities lending around dividend record dates. Because of these practices, the dataset can become obfuscated. Christophe et al. $(2005,2007)$ discuss the problem in short-interest data arising from the aggregation of short positions from market participants with differing motivations (e.g. market makers, option-market arbitrageurs, traders expecting stock price declines). With stock lending data, an even greater number of motivations can exist, including financing purposes, and borrowing to vote the stock. A crucial issue for this study concerns dividend dates, since dividend tax arbitrage is common in practice. To minimize the risk that stock lending for 


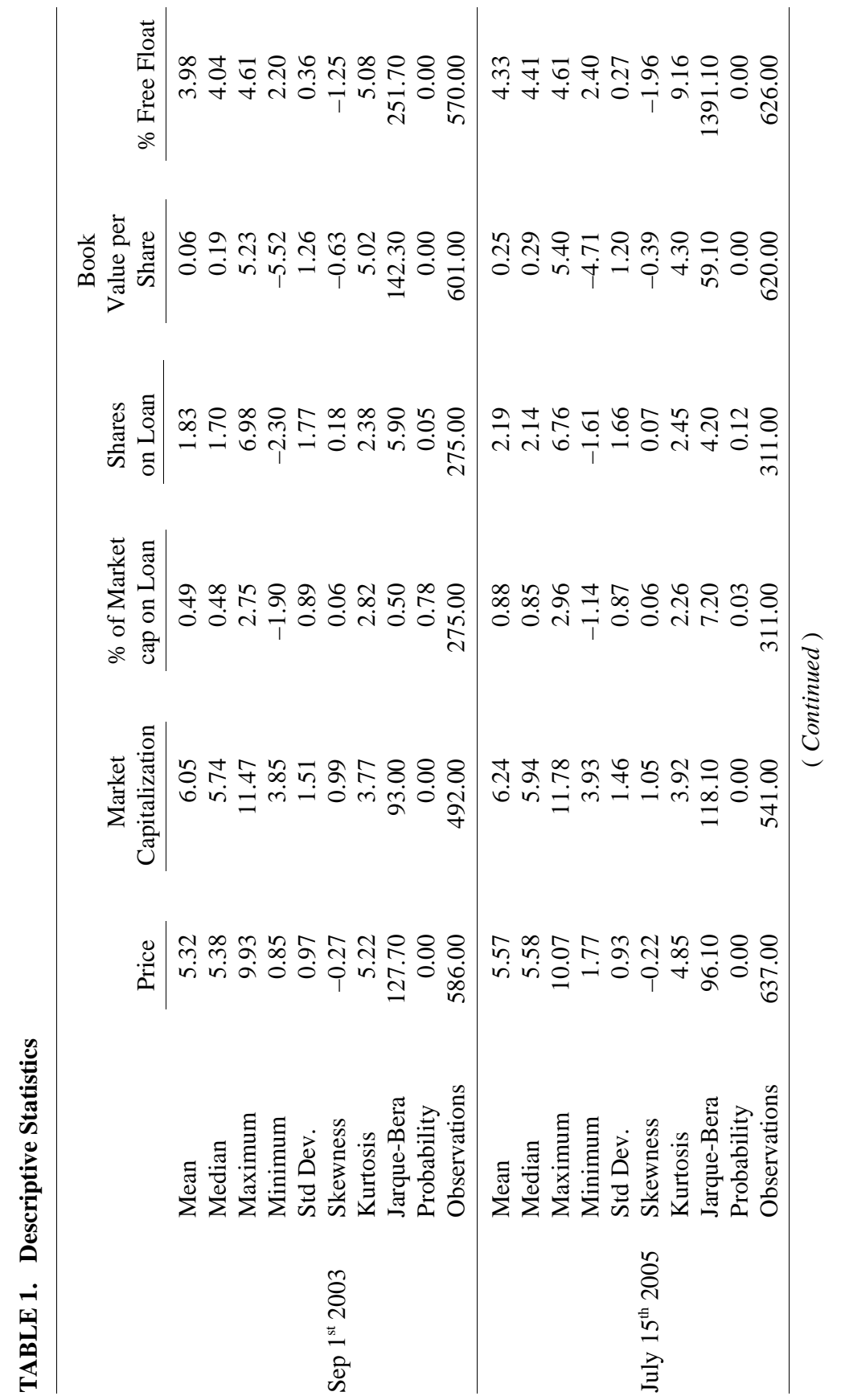




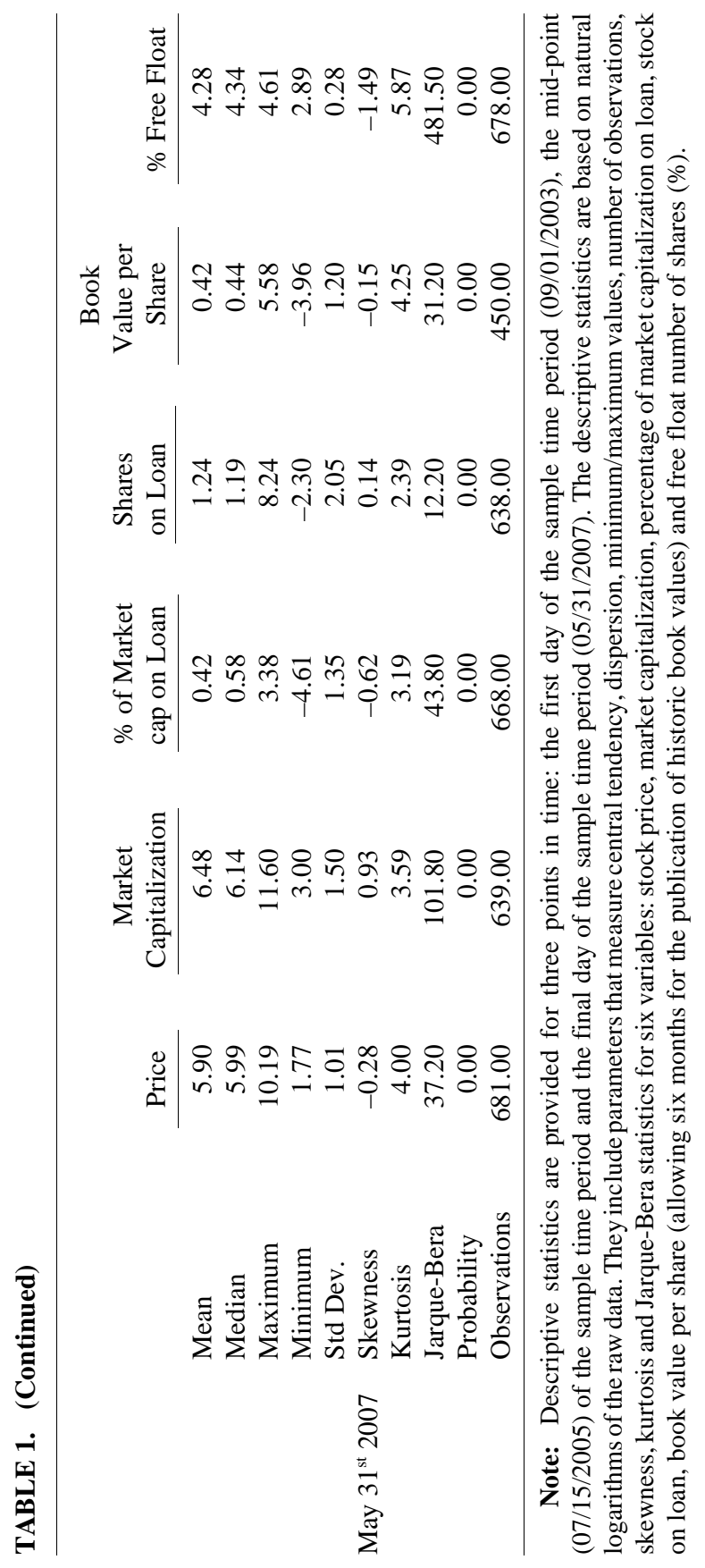


dividend tax arbitrage is confounded with borrowing to facilitate short selling, we remove data for three weeks before and after the dividend record date for each stock. This is consistent with the method employed by Saffi \& Sigurdsson (2007). ${ }^{2}$

Third, the extent to which market practitioners fail to report stock lending to the market authorities is a further limitation on the use of stock lending data as a proxy for short-selling. Discussions with practitioners involved in stock lending suggest this is an infrequent problem, but unavoidable.

Finally, derivatives can be used to effect transactions that are economically equivalent to short-selling (Ofek et al., 2004). The extent to which the use of derivatives to facilitate short selling is transmitted into the stock lending market influences the usefulness of stock lending data as a proxy for short-selling. Discussions with stock-lending practitioners suggests that the majority of, but not all, short-sale-equivalent trades using derivatives are ultimately hedged by the counter-parties to those trades, through borrowing stock and selling short.

Table 1 provides descriptive statistics for key variables for three points in time: the first day of the sample time period for which all the variables existed (09/01/2003), the last day of the sample time period (05/31/2007) and the mid-point (07/15/2005). We provide a series of dates as this is an unbalanced panel: new stocks enter the database over time while other stocks experience corporate activity such as bankruptcy or mergers.

The descriptive statistics are based on natural logarithms of the raw data. By using logarithms, we mitigate problems associated with skewness in several of the variables (including the percentage of market capitalization on loan). For each transformed variable shown, the means and medians are generally close together. The market capitalization and shares on loan data exhibit high dispersion. There is considerable variation in the book value per share variable over time.

\section{Methodology}

To start, we aim to establish the link between returns and short interest,

2. Most UK companies pay dividends twice a year, rather than the quarterly practice of US corporations. 
using a proxy for short interest - the natural logarithm of the Percentage of Market Capitalization on Loan - as the dependent variable. We note that using stock returns as an independent variable can result in confusion - an increase in returns essentially stands for the loss that short sellers face. Greater clarity is achieved by using stock price as the independent variable - it acts as a proxy for 'loss' in the same way as returns do (as they move in the same direction) and it is sufficient to establish the link between the loss-proxy and the short sellers' response. A more important reason for using price instead of returns as the independent variable in the first stage of the analysis, however, is that it makes an easier link with the second stage of the analysis, where we introduce a superior proxy for loss that reveals whether short-sellers react solely to price changes or whether they are driven in their actions by their own book losses. To create this superior proxy for loss, we require an estimate of the cost basis for short-sellers' positions in each stock.

\section{A. Estimating the Cost-Basis for Short-Sellers' Positions}

We refer to the price at which a short position is initiated as the "cost basis' of a short position. The cost basis of a position is important because it is the difference between this and the market price of a security that determines if a position is at a profit or loss. We estimate the average cost basis of short-sellers using a procedure similar to the volume weighted average purchase price technique used by Brown et al. (2002) for long-only investors. We take stock prices and the number of shares on loan for the first company in the dataset and identify the first occasion in the series when the number of shares on loan increases. We assume that this increase in shares on loan represents shares borrowed for the purpose of short-selling and estimate the price at which this was done as the average of the opening and closing prices for the stock on that date. This becomes our initial estimate of the cost basis of all short positions for this stock. This estimate is updated on the next occasion when shares on loan increases (we ignore days when 'shares on loan' is unchanged or decreases, as there are no net new short positions established on these days). With each additional estimate of the price at which shares are shorted for a particular day, we refine our previous estimate of the cost basis of all short sellers. To do this, we calculate the weighted average cost basis at which the positions were established, weighted by the number of shares shorted on each occasion. This 
approach allows us to gradually build our estimate, based on published data. As the estimate is updated each day on which there is a rise in shares on loan, the estimate is expected to improve over time. Cohen et al. (2007) find that the median contract length is 11 days. Accordingly, the formation period for each stock in the sample should cover at least several weeks. As early estimates are likely to be poor, we choose a formation period of one year. The whole procedure is repeated for the next stock and so on. Regression analysis is undertaken using the period after the one-year formation period. However, the 'estimated cost basis' for each stock is updated every day beyond the formation period. The 'estimated cost basis' is incorporated into the regression analysis in the following manner. The difference between the 'estimated cost basis' and the share price is found for each occasion that a company's share price rises above the 'estimated cost basis' - this represents the short sellers' loss. For ease of interpretation the absolute values of this series is taken. In the second stage of analysis this loss series enters the regressions along with the price variable. This is done to see whether short-sellers react to the price change or instead to their own book loss, as price might have its own effect on the 'percentage of market capitalization on loan' series, independent of the short-sellers' book loss.

Throughout the study, we incorporate control variables into the regressions. These control variables are market capitalization, market-to-book ratio and free float number of shares, this latter being a proxy for the availability of stock loans. This study runs the following set of regressions. For the first stage of the analysis:

$$
\begin{aligned}
& \ln (\text { Percentage of Market Capitalization on Loan })_{t}= \\
& \alpha+\beta\left(\text { lnPrice }_{t}\right)+\gamma\left(\text { Market Capitalization }_{t}\right)
\end{aligned}
$$

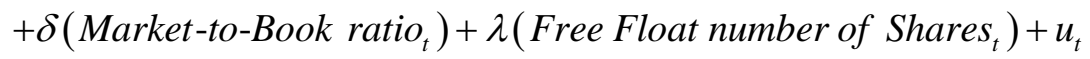

For the second stage, we introduce the loss series as an independent variable: 


$$
\alpha+\theta\left(\text { lnLoss }_{t}\right)+\beta\left(\text { lnPrice }_{t}\right)+\gamma\left(\text { Market Capitalization }_{t}\right)
$$

$+\delta\left(\right.$ Market-to-Book ratio $\left._{t}\right)+\lambda\left(\right.$ Free Float number of Shares $\left._{t}\right)+u_{t}$

For the third stage, we introduce lagged forms of the loss series into the regressions to see if their effect diminishes with time. We also investigate the regression based solely on the top quintile of the loss series as a robustness test.

As a further check, we also consider the change in short interest (i.e. change in the percentage of market capitalization on loan) as the dependent variable:

$$
\begin{aligned}
& \Delta(\text { Percentage of Market Capitalization on Loan })= \\
& \alpha+\theta\left(\operatorname{lnLoss}_{t}\right)+\beta\left(\text { lnPrice }_{t}\right)+\gamma\left(\text { Market Capitalization }_{t}\right) \\
& +\varsigma\left(\text { Percentage of Market Capitalization on Loan }{ }_{t}\right)
\end{aligned}
$$

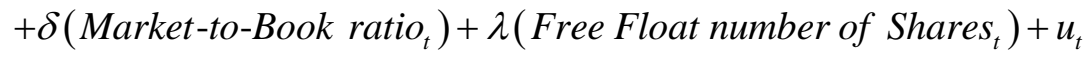

where the series 'percentage of market capitalization on loan' on the right-hand side acts as an additional control variable.

For each regression, we take care of the firm effect parametrically by including firm dummies and we use clustered by time period standard errors to eliminate the non-fixed time effect. Petersen (2009) recommends starting with an analysis of a panel dataset to find out whether there is a time effect, firm effect, or both, and whether those effects are permanent or temporary. In the spirit of Petersen, we investigate the dataset to determine the most appropriate procedure. As a starting point, it is reasonable to assume that the dataset has some firm effect, i.e. the residuals for a particular company are correlated along the time period, and this is corroborated by an inspection of the correlograms. In other words, there are factors that are not explicitly included in our regressions that influence the dependent variable (percentage of market capitalization on loan) that are either constant or changing over time, but that differ from firm to firm. Such factors could, for example, be a firm's management capabilities or its competitive advantage. It is difficult to evaluate whether this factor stays constant 
over the entire sample period or, say, decays over time. Mauboussin and Johnson (1997) show that a firm's competitive advantage period generally varies between two and twenty years. This suggests that any qualitative judgment would be highly subjective.

Secondly, we consider that the dataset might have some time effect. In other words, any market shock would affect all firms in the market to some extent. This is particularly relevant for our sample, where all the stocks are traded on one exchange. The question, however, remains as to whether or not all firms would be affected to the same extent by such a shock. It is reasonable to hypothesize that some firm effects and time effects are present. Any effects will include a fixed part, because temporary effects can always be adjusted so as to incorporate a fixed component. On this basis, we include firm and time dummies in the regression to take care of the fixed components of the firm effects and time effects. We next employ quantitative analysis to check whether there is a temporary component of the firm and time effects. This is done by comparing (for each regression) the standard errors clustered by time period and the standard errors clustered by firm to the benchmark of the White standard errors. Because each type of standard error is already adjusted for the problem of heteroskedasticity, the difference between standard errors would be the result of temporary effects. As each regression also includes firm dummies and time dummies to take care of any fixed effects, if the standard errors clustered by firm, for example, are very different from White standard errors, then there is a firm effect in the data that has not been eliminated by the firm dummies. In other words, because firm dummies eliminate fixed firm effects, there must also be a temporary firm effect in the data.

To this effect, for each of the equations above, the regression analysis was run using the following different types of standard error: White, clustered by firm and clustered by time period. ${ }^{3}$ The results obtained using the White and clustered by firm standard errors were very similar, while the results obtained using clustered by time period standard errors were starkly different. This suggests that our data has fixed firm effects and temporary time effects. In such a situation, Petersen recommends taking care of the firm effect parametrically (by including firm dummies) and using clustered by time period standard errors to eliminate the non-fixed time effect. Time dummies are also

3. The full results are not shown here to save space but are available on request from the authors. 
kept in the regressions for the reasons discussed above. The results of these regressions are reported in section IV below.

Finally, if evidence emerges that short-sellers cover their positions in response to losses, it is natural to question if this short-covering has a cost to short-sellers, in the sense that stocks under-perform subsequent to short-covering. Having covered their positions, short-sellers would fail to benefit from any such under-performance and this would represent an opportunity cost. For each stock, we identify each occasion that the stock price rises above the estimated weighted-average cost basis for short-sellers, and where the number of shares on loan falls on that day and also on the following day, indicating short-covering. For each of these occasions, we calculate the cumulative abnormal stock return for 5, 10 and 30 days after the day on which the stock price rises above the short-sellers' cost basis. We form a portfolio of such stocks and test the hypotheses of zero cumulative abnormal returns for the 5 , 10 and 30 day periods. The portfolio of stocks is equally-weighted, in order to prevent a small number of large-capitalization stocks from defining the results for the whole sample.

\section{Results}

Results for regression analysis using the specifications given in equations (1) and (2) from section III above are presented in table 2:

Panel A in table 2 shows that the coefficient for the stock price variable is negative but not statistically significant. The coefficient for the control variable 'market capitalization' is negative and statistically significant at the $0.1 \%$ level, suggesting that as market capitalization rises, short interest diminishes. In other words, short-sellers show a preference for targeting smaller companies.

In Panel B, the short-sellers' book loss variable is introduced to the analysis. The price variable is retained as it could have its own effect on the market capitalization on loan besides being a proxy for the loss. We note the problem of correlation between the two variables, but wish to consider as best as possible the relative importance of the two variables. Subject to this limitation, results from the first regression in Panel B show that the coefficient for the book loss variable is negative and significant at the $1 \%$ level. The coefficient for the price variable remains statistically insignificant. This suggests that short sellers cover their positions in response to their own book losses (not merely in 


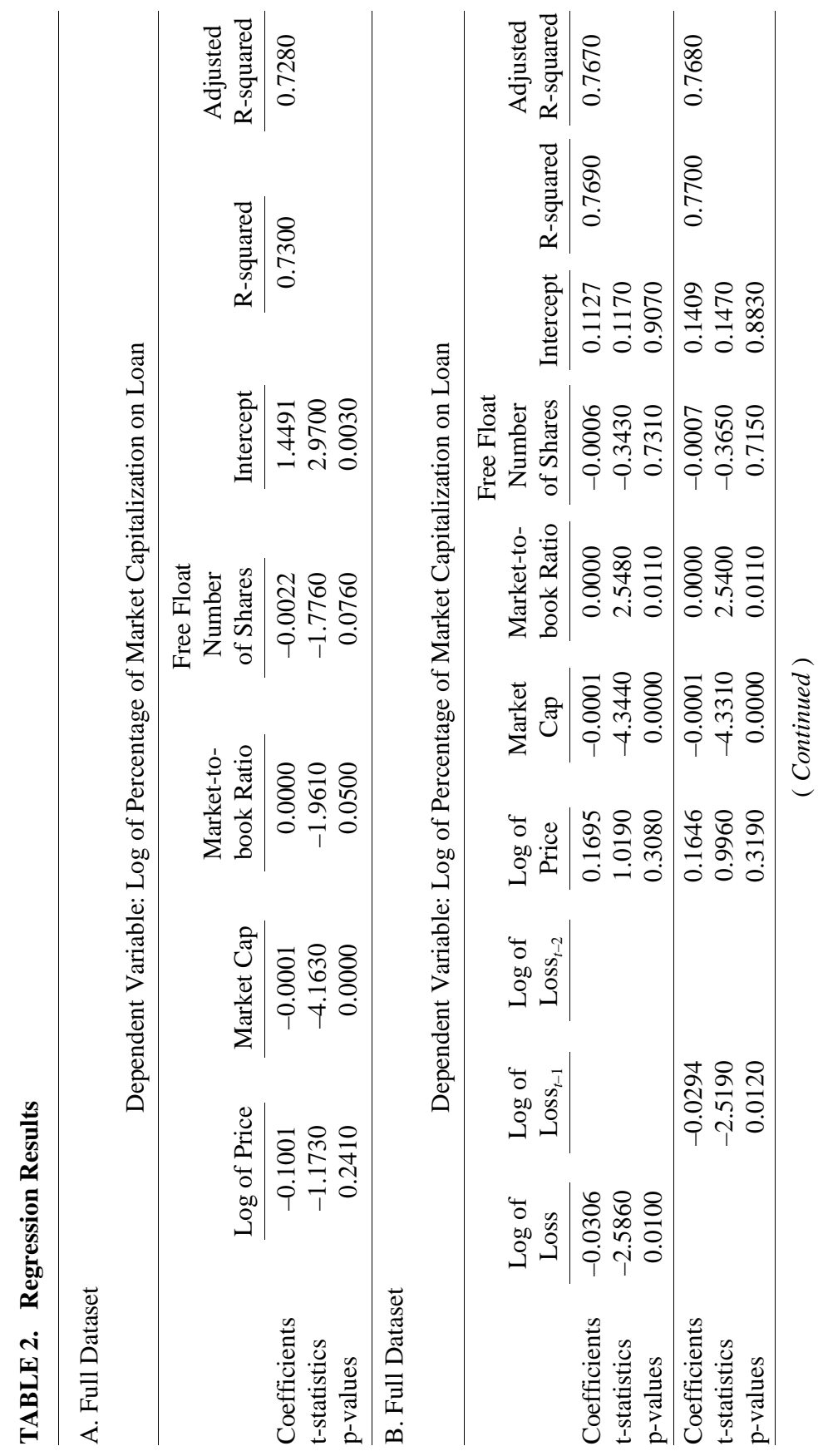




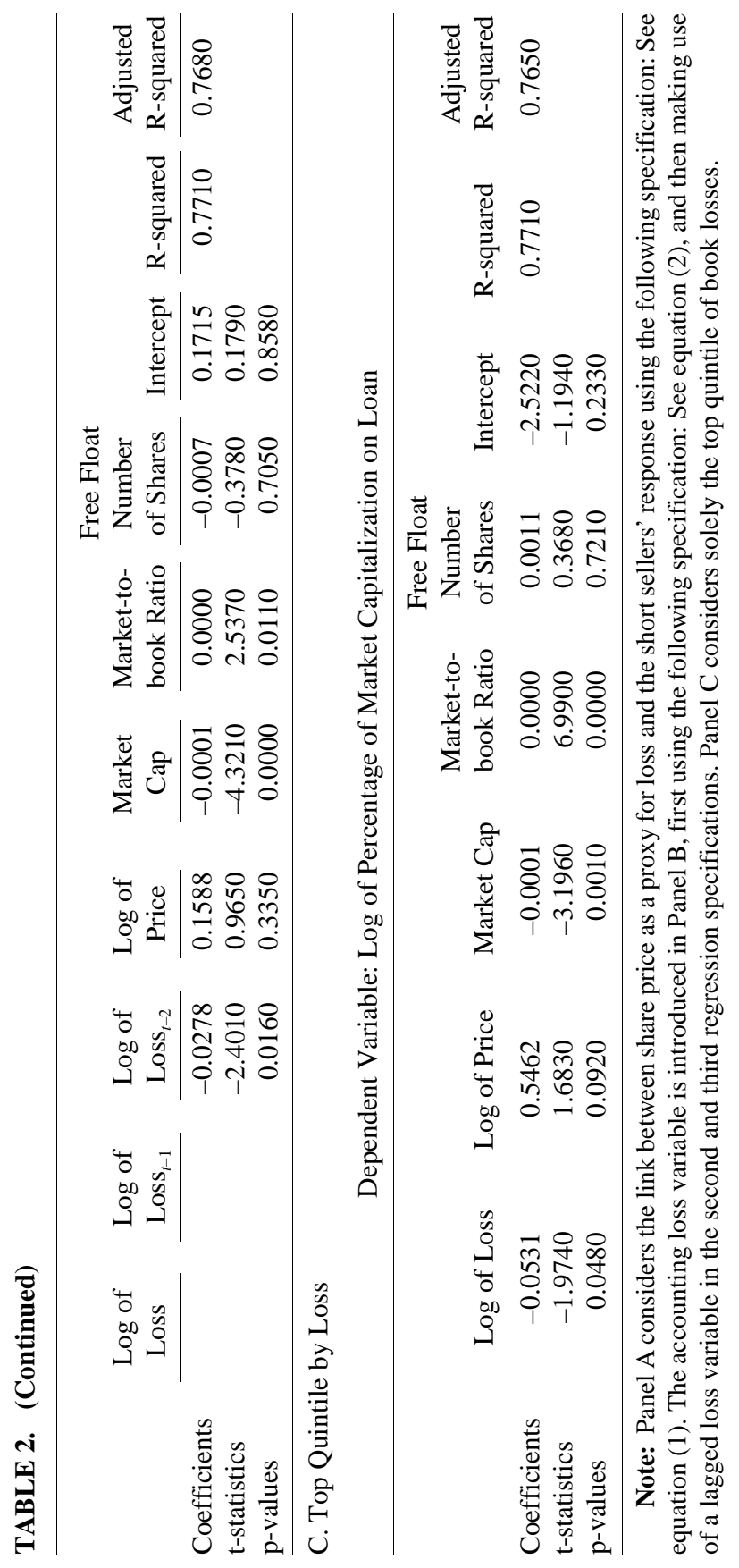


response to rising share prices).

The coefficient for the 'market to book ratio' control variable is positive and statistically significant at the 5\% significance level, suggesting short-sellers' preference for targeting 'glamour' stocks. The 'percentage of free float shares' variable, a control variable for short sale constraints, is not significant. A plausible explanation for this is that the majority of firms in the sample have a large free float, as noted in the descriptive statistics section. In fact, only 32 (out of 681) stocks have a mean percentage of free float shares below $40 \%$. Thus, short sale constraints do not appear to significantly influence this sample of stocks.

Benefiting from the daily dataset, we are also able to examine the relationship between short-interest and lagged accounting losses. In the second and third specifications of Panel B, the loss variable is replaced with a lagged loss variable (a one day and two day lag, respectively). The coefficient on the loss variable that is lagged by one day, although statistically significant, is smaller than the coefficient on the non-lagged loss variable and the coefficient on the loss variable lagged by two days is smaller than the coefficient on the loss variable lagged by one day. This highlights the advantages of using daily data in understanding the actions of short-sellers. Indeed, these results suggest that many short sellers (but not all) react to a loss quickly - within one day. However, as short-sellers are not a homogenous group, some might react to losses only when, for example, accumulated losses lead to margin calls or amount to a certain percentage of capital. Furthermore, individual short-sellers will each have different cost bases.

We test the robustness of the main regression specification using a restricted sample of the top quintile of the loss series. This subset represents the 'large loss' series. Regression results are shown in Panel $\mathrm{C}$ of table 2. The coefficient of the loss variable is negative and statistically significant (at the 5\% significance level) with the variables for stock price and free float number of shares being statistically insignificant. The explanatory power of this regression is also large, with the adjusted $\mathrm{R}^{2}$ being around $77 \%$. The coefficient of the loss variable from this regression is of greater magnitude than the equivalent coefficient from the regression on the non-restricted sample presented in the Panel B. This suggests that short-covering as a response to book losses is greater for larger losses.

As a further check, we undertake a regression in accordance with equation (3) in section III above. In this specification, the dependent 
variable is the change in the market capitalization on loan - similar to the approach undertaken by Gamboa-Cavazos and Savor (2007). The coefficients of the variables are much smaller than the coefficients of the previous regression specifications, although most are statistically highly significant. The explanatory power of this regression $\left(\mathrm{R}^{2}\right.$ is around $2 \%$ and adjusted $\mathrm{R}^{2}$ is around $1 \%$ ) is also far smaller than the explanatory powers of the previous regressions. This is, however, not surprising as coefficients here represent change in the change of the market capitalization on loan. Nevertheless, the magnitude of the coefficients and of the explanatory power is in line with those found by Gamboa-Cavazos and Savor. It is also important to mention the interpretation of these coefficients. The coefficient on the loss variable (positive and statistically significant at the $1 \%$ significance level) tells us that the greater the loss, the greater the change in the market capitalization. In other words, large losses trigger a stronger reaction among short-sellers. This result has an intuitive appeal to it.

Next, we test for short covering at different levels from simply the average cost basis of short-sellers. In particular, we examine when stock prices reach $2.5 \%$ and $5 \%$ above the cost basis. This is inspired by the belief (gained from interviews with short-sellers) that some short-sellers force themselves to sell positions once losses exceed a pre-defined threshold. Such mechanisms are generally known as 'stop-losses'. The form of the regression is similar to that in the rest of the study, but with one excpetion: in order to examine short covering at $2.5 \%$ and $5 \%$ above the cost basis, the loss series is presented in relative or percentage terms (relative to price) and then only those data points that were $2.5 \%$ $(5 \%)$ above the average cost basis of short-sellers were recorded. The loss series here is in absolute values. Then the logarithm of this series was taken before it entered the regression. Table 3 shows that the coefficient on the loss variable becomes more economically and statistically significant at higher levels above the cost basis.

It is natural to consider if there is a cost, in terms of investment performance, to short-sellers who make use of stop losses. Table 4 below presents the cumulative abnormal returns for stocks that have risen above the corresponding estimated weighted-average cost basis for short-sellers, and where short-covering has taken place.

Cumulative abnormal returns for 5, 10 and 30 days after the day on which the stock rises above the estimated short-sellers' cost basis are all positive and statistically significant. There is, however, an endogeneity problem associated with such situations: the act of short covering could 


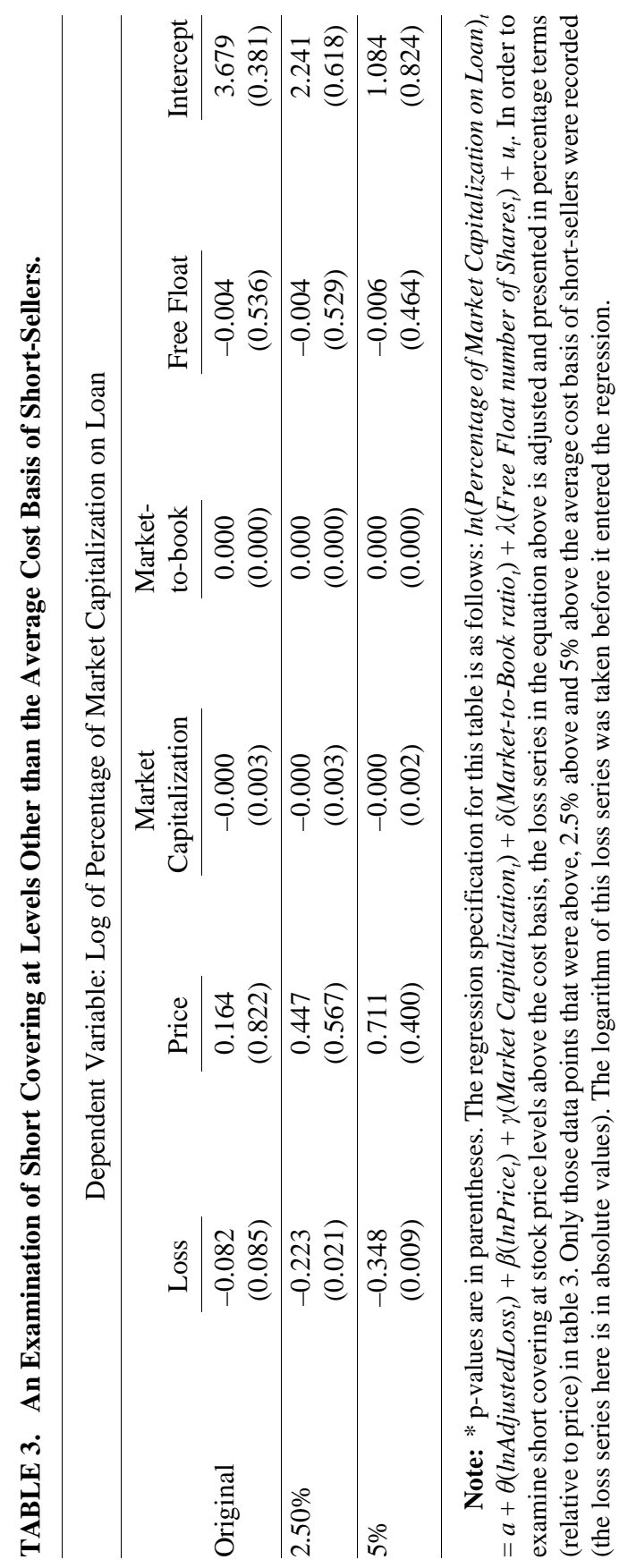


TABLE 4. Cumulative Abnormal Returns after Short-Covering

\begin{tabular}{lllc}
\hline & 5 days & 10 days & 30 days \\
\hline Mean & 0.0011 & 0.0023 & 0.0084 \\
Standard Deviation & 0.029 & 0.043 & 0.070 \\
Degrees of Freedom & 15760 & 15613 & 15069 \\
t-statistic & 4.51 & 6.62 & 14.73 \\
p-value & 0.0000 & 0.0000 & 0.0000 \\
\hline
\end{tabular}

Note: The Table reports cumulative abnormal returns (CARs) calculated on an equal-weighted basis for all stocks from days on which two conditions are met: the stock rises above the estimated weighted-average cost basis for short-sellers of that stock; and the number of shares on loan falls that same day and the following day. CARs are calculated for 5,10 and 30 days after each day on which the two conditions are met.

have market impact, leading in and of itself to stock price increases. It is thus difficult to interpret the above results as evidence that short-covering in response to losses prevents further losses to a short-seller. Nevertheless, it can be argued that there is no evidence of an investment performance cost (other than transaction costs) to short-sellers from immediate short covering upon loss. From the perspective of a risk manager proposing the use of stop losses, this is an important finding.

\section{Discussion and Analysis}

We find significant evidence of short-covering in response to book losses in individual stocks. This finding is inconsistent with the notion that short-sellers are averse to realizing losses. This has important implications for asset pricing. Aversion to realizing losses is a bias observed in empirical studies of many types of market participant, including some professional investors. However, we show that this bias is not present amongst short-sellers, a group that is particularly associated with arbitrage and price setting.

A possible interpretation is that short-sellers, as 'sophisticated' market participants, are naturally less prone to loss realization aversion than other investors. Alternatively, those short-sellers that are free from this bias might prove more successful and gain a greater share of capital, such that short-sellers in aggregate appear not to suffer from loss realization aversion. Locke and Mann (2000) show that "there is evidence that trading success is negatively related to the degree of loss realization aversion." Short-sellers aware of such evidence might 
respond by adapting their behavior so as to remove this bias.

A further plausible explanation, however, is that short-sellers employ risk control mechanisms that have the effect of mitigating loss realization aversion. Although neither legal nor contractual constraints force short-sellers to close their positions at any particular level of loss, there are practical reasons to cover short positions in response to accounting losses. A key reason is that short-sellers face theoretically unlimited losses. By systematically crystallizing small losses through the use of stop losses, short-sellers are able to contain this risk. The use of established risk techniques such as dynamic hedging and position limits are also consistent with realizing losses in short positions.

The literature on stock price momentum effects also offers an explanation for short-sellers covering positions in response to losses. Jegadeesh and Titman $(1993,2001)$ show that momentum strategies ('buying winners and selling losers') based on prior performance can generate significantly positive returns for holding periods of 3 to 12 months. Short-sellers might believe that short positions that fall to a loss shall continue to experience losses in the future. Although subject to an endogeneity problem, table 6 shows that there is a statistically significant (albeit economically modest) momentum effect for such stocks on a 5, 10 and 30 day horizon.

The desire to maintain portfolio diversification provides a further alternative explanation for short-covering. When short positions lose money, they become a larger part of the portfolio. Reducing such positions can help to maintain portfolio diversification.

For taxable investors, there could be tax advantages associated with crystallizing losses. However, it is widely believed that short-selling is concentrated amongst funds that generally operate in tax-free, 'offshore' environments. Accordingly, tax reasons are a less likely explanation of the observed results.

Constrained capital provides another plausible explanation for the tendency of short-sellers to cover in response to losses. Shleifer and Vishny (1997) argue that arbitrageurs in practice are generally agents working for owners of capital. Arbitrageurs face the risk that ill-informed, disillusioned investors will withdraw their capital in response to losses at the portfolio level, even though the underlying positions might be attractive. This gives arbitrageurs a strong incentive to avoid losses at the portfolio level. By systematically accepting small losses in individual stocks, this reduces the risk of large losses that might tip the overall portfolio into loss. An additional consideration is that short positions that fall to a loss could require the provision of 
further margin or collateral (to protect the stock lender or counter-party to a synthetic short position). This can cause additional strain on the limited capital available to short-sellers. Such strain is mitigated by covering short positions that fall to a loss.

We next consider 'myopic loss aversion' as an explanation for the observed phenomenon. Short-sellers could be loss averse, with the degree of loss aversion depending on prior gains and losses. After experiencing losses, short-sellers could become more loss averse and so cover their positions. Fellner and Sutter (2008) conduct a series of experiments in a long-only environment to identify the causes of 'myopic loss aversion' and find that inappropriately short investment horizons and high feedback frequency contribute almost equally to this phenomenon. However, under an efficient markets framework, an un-hedged short position in a risky security has a negative expected return. Only with a mispricing story will the risky security have a positive expected return, and even then, only in the short-term because of the negative beta problem (Dyl, 1975). Myopic loss aversion - which manifests itself in a tendency to shun attractive long-term investments because of an aversion to short-term losses - should not apply to situations involving negative long-term expected returns. Indeed, given that a mispricing story is required to make un-hedged short-selling worthwhile, accepting losses appears rational for two reasons: first, if a short-seller believes that the market has mispriced a stock, but finds his short position falling to a loss, this suggests that his original mispricing thesis could be mistaken. Accepting the mistake (covering the short position) is rational in light of the negative expected long-term return. Second, it should be clear to the short-seller that as a position falls to a loss, synchronization risk (concerned with uncertainty about the market timing decisions of other rational arbitrageurs and thus the timing of the price correction) is heightened. Abreu and Brunermeier (2002) suggest 'delayed arbitrage' as a response to synchronization risk. This is consistent with short covering and returning to short the stock later, when other arbitrageurs have learned of the over-valuation. Myopic loss aversion does not provide an adequate explanation for the observed results.

Our findings contribute to the literature on loss realization aversion and the 'disposition effect'. We show that a sophisticated group of traders, strongly associated with price setting, is not averse to realizing losses. This is consistent with the findings of Brown et al., 2002 (who find that "traders instigating larger investments tend to be less, if not entirely unaffected by the disposition bias") and Da Silva Rosa et al., 
2005 (who observe that UK managed funds do not exhibit the disposition effect, once proxies for liquidity and value are taken into account). Thus, empirical evidence is emerging to show that larger and more sophisticated investors, who are most likely to set prices in markets, do not appear to suffer from the disposition effect.

There is, however, a potential 'unintended consequence' for short-sellers, arising from their response to book losses. The systematic crystallization of losses represents a form of predictable behavior. By knowing (or being able to estimate) the capital strength and cost basis of short-sellers, predators should be able to anticipate short-covering and so position themselves to benefit from the market impact of such trades. This is similar to the pattern described by Chen et al. (2006), whereby predators anticipate rebalancing by index funds and take advantage of the market impact of index fund investors.

Furthermore, it could be possible for one or more manipulators to induce short-covering by placing buy orders when a stock price is close to the average cost basis of short-sellers. Where the market impact of such trades pushes the stock price above the cost basis of short-sellers, short-covering ensues, placing further upwards pressure on the stock price when liquidity is constrained. The manipulator closes his long position by selling stock to a covering short-seller, 'earning' a profit in the process.

\section{Conclusions}

This study fills an important gap in the literature on loss-aversion with respect to a sophisticated sub-set of market participants. Our findings should be of interest to researchers in behavioral finance and asset pricing. We find that short-sellers do not exhibit an aversion to realizing book losses, but instead accept their losses or 'mistakes' systematically. Our evidence shows that a group that is believed to play an important role in setting asset prices does not suffer from an aversion to realizing losses. This has positive implications for market efficiency.

Accepted by: Prof. R. Taffler, Guest Editor, December 2009

Prof. P. Theodossiou, Editor-in-Chief, December 2009

\section{References}

Abreu, D., and Brunnermeier, M. 2002. Synchronization Risk and Delayed 
Arbitrage. Journal of Financial Economics, 66 (2-3), 341-360.

Ackert, L.F., and Athanassakos, G. 2005. The Relationship between Short Interest and Stock Returns in the Canadian Market. Journal of Banking and Finance, 29, 1729-1749.

Aitken, M.J.; Frino, A.; McCorry, M.S.; and Swan, P.L. 1998. Short Sales are Almost Instantaneously Bad News: Evidence from the Australian Stock Exchange, Journal of Finance, 53 (6), 2205-2223.

Au, A. S.; Doukas, J. A; and Onayev, Z. 2007. Daily Short Interest, Idiosyncratic Risk, and Stock Returns. Working Paper (November, 2007).

Barberis, N., and Huang, M. 2001. Mental Accounting, Loss Aversion, and Individual Stock Returns. Journal of Finance, 56 (4), 1247-1292.

Barberis, N.; Huang, M.; and Santos, T. 2001. Prospect Theory and Asset Prices. Quarterly Journal of Economics, 116, 1-53.

Benartzi, S., and Thaler, R. 1995. Myopic Loss Aversion and the Equity Premium Puzzle. Quarterly Journal of Economics, 110, 73-92.

Biais, B.; Bisiere, C.; and Decamps, J. 1999. Short Sales Constraints, Liquidity and Price Discovery: An Empirical Analysis on the Paris Bourse. European Financial Management, 5, 395-409.

Boehmer, E.; Jones, C.M.; and Zhang, X. 2008. Which Shorts are Informed? Journal of Finance, 63 (2), 491-527.

Bonner, S., and Pennington, N. 1991. Cognitive Processes and Knowledge as Determinants of Auditor Experience. Journal of Accounting Literature, 10, $1-50$

Brown, K.; Harlow, V.; and Starks, L. 1996, as cited by Shefrin, H., 2002, Beyond Greed and Fear, Oxford University Press.

Brown, P.; Chappel, N.; Da Silva Rosa, R.; and Walter, T. 2002. The Reach of the Disposition Effect: Large Sample Evidence across Investor Classes. Working Paper, The University of Western Australia.

Burns, P. 1985. Experience in Decision Making: A Comparison of Students and Businessmen in a Simulated Progressive Auction, in V. L. Smith, ed. Research in Experimental Economics, JAI Press, Greenwich

Chen, H.; Noronha, G.; and Singal, V. 2006, Index Changes and Losses to Index Fund Investors, Financial Analyst Journal, 62, 4, 31-45

Christensen-Szalanski, J., and Beach, L.R. 1984. The citation Bias: Fad and Fashion in the Judgment and Decision Literature. American Psychologist, 39, 75-78.

Christoffersen, S.E.K.; Geczy, C.C.; and Musto, D.K. 2005. Crossborder Dividend Taxation and the Preferences of Taxable and Non-taxable Investors: Evidence from Canada. Journal of Financial Economics, 78 (1), 121-144.

Christoffersen, S.E.K.; Reed, A.V.; Geczy, C.C.; and Musto, D.K. 2002. The Market for Record-Date Ownership. EFA 2002 Berlin Meetings Presented Paper. Available at SSRN: $\underline{\text { http://ssrn.com/abstract=302522 }}$

Christophe, S.E.; Ferri, M.G.; and Angel, J.J. 2005. Short-Selling and the 
Accrual Anomaly. Working Paper, George Mason University.

Christophe, S.E.; Ferri, M.G.; and Angel, J.J. 2007. Should Owners of NASDAQ Stocks Fear Short-Selling? Journal of Portfolio Management, 33 (3), 122-131.

Cici, G. 2005. The Relation of the Disposition Effect to Mutual Fund Trades and Performance. Available at SSRN: http://ssrn.com/abstract=645841

Cohen, L.; Diether, K.B.; and Malloy, C.J. 2007, Supply and Demand Shifts in the Shorting Market. Journal of Finance, 62 (5), 2061-2096.

Coval, J.D., and Shumway, T. 2001. Do Bahavioral Biases Affect Prices? Working Paper, University of Michigan.

D’Avolio, G. 2002. The Market for Borrowing Stock. Journal of Financial Economics, 66, 271-306.

Da Silva Rosa, R.; To, H.M.; and Walter, T. 2005. Evidence Contrary to the Disposition Effect amongst UK Managed Funds. Working Paper, The University of Western Australia.

Dechow, P.M.; Hutton, A.P.; Meulbroek, L.; and Sloan, R.G. 2001. Short Sellers, Fundamental Analysis, and Stock Returns. Journal of Financial Economics, 61, 77-106.

Dhar, R., and Zhu, N. 2008. Up Close and Personal: An individual Level Analysis of the Disposition Effect. Working Paper, Yale School of Management.

Dyl, E.A. 1975. Negative Betas: the Attractions of Selling Short. Journal of Portfolio Management, 3, 74-76.

Fama, E., and French, K. 1993. Common Risk Factors in the Returns on Stocks and Bonds. Journal of Financial Economics, 33, 3-56.

Fama, E., and MacBeth, J. 1973. Risk, Return and Equilibrium: Empirical Tests. Journal of Political Economy, 81 (3), 607-636.

Fellner, G., and Sutter, M. 2008. Causes, Consequences, and Cures of Myopic Loss Aversion - an Experimental Investigation. Working Paper, University of Innsbruck.

Frazzini, A. 2006. The Disposition Effect and Underreaction to News. Journal of Finance, 61 (4), 2017-2046.

Gamboa-Cavazos, M., and Savor, P. 2007. Holding on to your Shorts: When do Short-Sellers Retreat? Harvard University Working Paper.

Garvey, R., and Murphy, A. 2004. Are Professional Traders too Slow to Realize their Losses? Financial Analysts Journal, 60 (4), 35-43.

Geczy, C.C.; Musto, D.K.; and Reed, A.V. 2002. Stocks are Special Too: an Analysis of the Equity Lending Market. Journal of Financial Economics, 66, 241-269.

Genesove, D., and Mayer, C. 2001. Loss Aversion and Seller Behavior: Evidence from the Housing Market. The Quarterly Journal of Economics, 116, 4, 1233-1260.

Grinblatt, M., and Han, B. 2004. Prospect Theory, Mental Accounting, and Momentum. Working Paper, UCLA. 
Haigh, M.S., and List, J.A. 2005. Do Professional Traders Exhibit Myopic Loss Aversion? An Experimental Analysis. Journal of Finance, 60 (1), 523-534.

Heisler, J. 1994. Loss Aversion in Futures Markets: An Empirical Test. The Review of Futures Markets, 13, 793-822.

Holt, C., and Villamil, A. 1986. The Use of Laboratory Experiments in Economics: An Introductory Survey, in S. Moriarity, ed. Laboratory Market Research, University of Oklahoma Press, Norman, OK

Jegadeesh, N., and Titman, S. 1993. Returns to Buying Winners and Selling Losers: Implications for Stock Market Efficiency. Journal of Finance, 48 (1), 65-91.

Jegadeesh, N., and Titman, S. 2001. Profitability of Momentum Strategies: an Evaluation of Alternative Explanations. Journal of Finance, 56 (2), 699-720.

Johnson, E.; Gachter, S.; and Herrmann, A. 2006. Exploring the Nature of Loss Aversion. Discussion paper, University of Nottingham

Kahneman, D., and Tversky, A. 1979. Prospect Theory: An Analysis of Decision under Risk. Econometrica, 3, 47(2), 263-291.

Locke, P., and Mann, S.C. 2000. Do Professional Traders Exhibit Loss Realization Aversion? Working paper, George Washington University.

Loncarski, I.; Ter Horst, J.; and Veld, C. 2009. The Rise and Demise of the Convertible Arbitrage Strategy. Financial Analysts Journal, 65 (5), 35-50.

MacKenzie, M., and Henry, Ó.T. 2008. The Information Content of Trading Volume and Short-Sales. Working Paper, Cambridge University.

Mauboussin, M., and Johnson, P. 1997. Competitive Advantage Period "CAP”, Financial Management, 26, 2, 67-74

Odean, T. 1998. Are Investors Reluctant to Realize their Losses? Journal of Finance, 53, 1775-1798.

Ofek, E.; Richardson, M.; and Whitelaw, R.F. 2004. Limited Arbitrage and Short Sale Restrictions: Evidence from the Options Market. Journal of Financial Economics, 74, 3-5-342.

Petersen, M.A. 2009. Estimating Standard Errors in Finance Panel Data Sets: Comparing Approaches. Review of Financial Studies, 22, 435-480.

Poitras G. 2002. Short Sales Restrictions, Dilution and the Pricing of Rights Issues on the Singapore Stock Exchange. Pacific-Basin Finance Journal, 10, 141-162.

Rabin, M., and Thaler, R. 2001. Risk Aversion. Journal of Economic Perspectives, 15, 219-232.

Saffi, P.A.C., and Sigurdsson, K. 2007. Price Efficiency and Short-Selling. Working Paper, London Business School (10/12/2007).

Senchack, A.J., and Starks, L.T. 1993. Short-Sale Restrictions and Market Reaction to Short-Interest Announcements. Journal of Financial and Quantitative Analysis, 28 (2), 177-194.

Shapira, Z., and Venezia I. 2000. Patterns of Behaviour of Professionally Managed and Independent Investors. Journal of Banking and Finance, 25, 
1573-1587.

Shefrin, H., and Statman, M. 1985. The Disposition to Sell Winners Too Early and Ride Losers Too long: Theory and Evidence. Journal of Finance, 40, 777-790.

Shefrin, H. 2002. Beyond Greed and Fear, Oxford University Press.

Shleifer, A., and Vishny, R. 1997. The Limits of Arbitrage. Journal of Finance, 52 (1), 35-55.

Thaler, R. 1980. Toward a Positive Theory of Consumer Choice. Journal of Economic Behavior and Organization, 1, 39-60.

White, H. 1980. A Heteroscedasticity-Consistent Covariance Matrix Estimator and a Direct Test for Heteroscedasticity. Econometrica, 48, 817-838.

$\mathrm{Xu}$, L., and Singal, V. 2009. Selling Winners, Holding Losers: Effect on Fund Flows and Survival of Disposition-Prone Mutual Funds. Available at SSRN: $\underline{\text { http://ssrn.com/abstract=1342889 }}$ 